\title{
Consumer Control Supportive Visualization
}

\author{
Gyenge Balázs ${ }^{1}$, Szeghegyi Ágnes, ${ }^{2}$ Szalay Gábor ${ }^{1}$, \\ Kozma Tímea $^{3}$
}

${ }^{1}$ Department of Operation Management and Logistics, Supply Chain

Management, Marketing and Tourism Institute, Faculty of Economy and Social Sciences, Szent István University, Páter Károly út 1, H-2100 Gödöllö, Hungary, gyenge.balazs@szie.hu, Gabor.Szalay@hu.bosch.com

${ }^{2}$ Keleti Károly Faculty of Business and Management, Óbuda University, Tavaszmező utca 15, H-1084 Budapest, Hungary, szeghegyi.agnes@kgk.uniobuda.hu

${ }^{3}$ Institute of Management and Business Informatics, Budapest Business School, Buzogány u. 10-12, H-1149 Budapest, Hungary, kozma.timea@uni-bge.hu

\begin{abstract}
It is becoming increasingly clear to professionals and leaders, in the economic sphere, that logistics and logistical approach are now not only a service area, but also clearly, part of a competitive winning strategy. We can see the benefits of system, both in the supply chain and in the flow actions of value-creating processes. Lean, is one of the most comprehensive and respected philosophies of value-creating process development, which now weaves the organization of resupply through its wide range of tools, including external relations on more and more levels. We have good reason to ask, what can be used to make the internal and external development of needs even more transparent and plastic? It is extremely important, that the consistency of demand and production is established in a customer-centered approach, which must be experienced by all participants, even those who are not directly related to the customers or their needs. In the meantime, in the growing competition between companies, the product itself is no longer the most important, but the services associated with it, for which we will need additional production information with the highest efficiency and economies of scale. At the same time, customer expectations are changing at a faster pace than ever, which requires not only extreme flexibility and preparedness, but also immediate (up-to-date) information. Considering of all this, this study looks for the technology to help display and monitor consumption, in a controlled way. This helps targeting the goals and identify workers, within the current situation, thus demonstrating the significance of visualization, through live examples. Our main question is to look at the "whats" and "whys" of visualization and once knowing that, we will also be better equipped to perform the visualization.
\end{abstract}

Keywords: Visualization; Visual Management; Consumption Control; Logistics; Lean 


\section{Introduction, the Importance of Consumption Control in Today's Economic Market}

In today's advanced, globalized manufacturing market, regions and national borders are no longer barriers to technology transfer. Large companies can access almost all technologies with sufficient capital and develop almost all skills among staff. Although there are significant differences in this area, the condition for staying in the market is noticeably pushed in the direction of how quickly and in what capacity we can serve customer needs and how cost-effectively we are able to do so. Consumer demand and continuous improvements in mass-customization, even in mass and series production, are shifting towards individual customized products, but quantitative fluctuations in customer demand are still very challenging. Although large customers (large suppliers, manufacturers, distributors) can reduce fluctuations with more accurate forecasting, to some extent through contracts, strategic cooperation and deliberate delay of orders, this problem can only be addressed effectively with a sufficiently advanced balanced or smoothing-pull system production scheduling.

Large companies using advanced production systems and producing customized products, and their senior colleagues, agree that push production, which accumulates large stocks, is no longer competitive [1]. To make finished and semi-finished products economically, assortment and continuously available, it is crucial to keep stocks at a low level, which will ensure the expected variance. To this end, a flexible production system, rapid changeover, fast lead times and predictable, stable technical (and human) capacity should be ensured on the technical side. From a non-technical point of view, it is necessary to clarify the forecasts by applying and/or developing the procedures and methods of the business, by defining inventory levels based on knowledge of the thorough process and customer behavior, and by providing and displaying accurate realtime information to the operating staff. One of the most effective ways to acquire knowledge to boost decision making or to develop a kind of decision support system, the visualization or so-called visual management method. In our study, we are looking for the technology to help display and monitor consumption in a controlled way and helps to target goals and identify workers with the current situation. We will try to demonstrate the significance of visualization through a live example. Our main question is to look at what and why to visualize it. And once we know that, we will also know how to do it. In the next section we'll continue to explore the importance of visualization in a specific industrial environment and look for opportunities for a visualization of consumer needs. 


\section{Literature Review on Visualization}

Many companies took serious efforts and introduced different physical visual tools that have been implemented to facilitate performance measurement or other communication in different processes. There are a lot of different tools to make better complex knowledge and overview about any value creation processes, like visual process boards [2], visualize ERP outputs [3] or any tools to make a better control on multiple supplier inputs or material flows (see MRPs [4-7]). It is crucial to bring together the different viewpoints or using visual process control to boost the communication and cooperation among the individual participants and make faster and more effective run on work lots, resources and processes throughout their organization. These systems act as an extension to statistics, metrics [8], and in themselves may be considered as a dynamic measurement system as they provide instant feedback and can be used to predict a probable outcome. [3] "Visual process management tools have been mainly developed by LEAN practitioners as communication aids and are used to help drive operations and processes in real time" [3]. Visual management is a way to visually communicate expectations, performance, quantities, standards, or warnings in a way that requires little or no prior training to interpret. We also use visualization if we have a numerous data like in case of Big Data. Different characteristic of the data and usage makes different visualization types in analytical literature sources, e.g. large volume of data makes 'Volume type of visualization', in case of multi-format data presentation gives 'Variety' type, and high data processing speed makes 'Velocity' type necessary. [9] One of the current challenges confronted by organizations is how to improve the ineffective delivery of information to their workforces in close-range communication [10]. The expected result of visual management is improved operations at a work setting [3] [11] [12]. Main advantage of visual management is the ability to instantly show the current state, desired extent, tracking dynamic changes, distributions, detect problems, wastes, signaling or highlighting decision points to anyone that observes, within only seconds. Effective visual management uses unique visual signs to communicate in many ways and it requires no any additional explanation to understand. We may share, build in, warn, stop, prevent any information or abnormalities to improving control of guidelines, performance and quality. In analysis tasks, the analyst usually wants to access a whole data array, but the data or tables are not communicate well, cannot be interpreted deeply so we need visualization. The first level of visualization is reduction of data sets like classification and different statistical methods and modelling. These approaches operate with multi gradient data aggregation and filtration, based on the relatedness of objects in concrete dataset by one or more criteria. The second level of visualization to use any $2 \mathrm{D}$ or $3 \mathrm{D}$ diagrams which makes the ability to see trends, similarities, seasonality, fluctuations, or margins for interpretation and so on. (e.g. temporal, hierarchical, network, multidimensional, geospatial diagrams) The effective visualization does not stop on only static image or data visualization, so the above 
problems become more significant in dynamic visualization. I believe that realtime tracking or dynamic visualization, can be the third level of visualization when the time has a special aspect to interpreting the meaning of data.

Graphical thinking is a very simple and natural type of data processing for a human being, so, it can be said, that image data representation is an effective method, which allows for easing data understanding and provides enough support for decision making [9]. Graphical data visualization increases the level of perception because human being loses the ability to acquire any useful information in any overloaded situation.

The collated experiences and implementation themes that have made as set of guidelines are crucial for new implementations and possible novel innovations [9] which boosts the communication and better control in a LEAN manufacturing process. Moreover, visual management can effectively be implemented in many other areas not just manufacturing [3] [13] (see examples on: Rolls Royce, Airbus, or other areas e.g. construction organizations, IT and software, service, commercial, educational, healthcare, or governmental service) [14-17]. In LEAN environment the visualization shorten lead times, reduce inventory, develop a safe working environment and even boost your profits and income. In the following study step-by-step we will elaborate a complete concept of gauge visualization of Kanban needs and guide for visual decision making.

\section{Material and Method, LEAN Summary and Principles of Consumption Control}

\subsection{The LEAN Methodology}

First of all, we would like to stress that the LEAN methodology is not "just" a production technology system for us, in which certain methods of procedure are defined or required. Like Japanese professionals, we stress that, above all, it is a more comprehensive philosophical concept that always favors solutions that provide the greatest usefulness and conformity at the moment (regardless of its origin or authors), so openness and willingness to give up previous innervation, traditional patterns, are important for its application and full understanding and making room for change.

By applying Lean's principles, you can achieve efficient and economical operation. The Lean methodology focuses on the process and not on the output of the process [18] or nor the function. At the same time, the starting principle is that all elements of production should be re-thought and developed on the basis of customer needs. 
In our methodology used below, we look at the processes of a multinational company as case-by-case examples, and then we carried out a secondary literature analysis, comparing the process and the area point by point with theoretical concepts, adapting them to local specificities with critical observations. First, let us review the interpretation of the principles based on the literature. According to one of the first newsreel and interpreters of the Lean concept (Womack - Jones, 1996) [19], the principles of Lean philosophy are the following, which we have paired with the most common tools according to Liker (2008) [20]:

- The concept of value and the definition of value - in which they stress that only activities and product elements are valuable, that are valuable to the buyer and what the buyer is willing to pay for, which also reveals real losses. To analyze it: analyze customer needs and how it is consumed.

- Value stream (value process) - when mapping the entire activity, it is clear which activities and time needs create value in the sense mentioned above and how they form a structure and chain. To analyze: you need to analyze the sources of loss, often used in the five why technique and value stream analysis (VSM).

- Flow - the more we talk about a process system, the more important is that the product and material flow is balanced, i.e. free of fluctuations, since bottlenecks and congestions hinder fast cycle times and high permeability at the level of the entire system. For analysis and development, in the spirit of JIT, pace-time planning, rapid changeover (SMED), built-in quality (JIDOKA), balanced production (HEIJUNKA), and developing one-piece flow are used.

- Pull - the key to reduce stocks dramatically is that every flow must be linked to demand and not the other way around, so there is a flow only if there is an order demand or signal in the balanced production chain, meaning there is no production for stocks except for intermediate buffers. For analysis and development, developing pull production (PULL), ensuring fast and automated supply is created by using KANBAN technology, and value flow analysis (VSM) is also often used.

- Improvement - continuous development and introduction of Kaizen, ensures small-step development in all areas, at all levels of the company, effectively, quickly and motivated, including the zero error principle. For analysis and development, we often use process standardization, continuous improvement KAISEN and transparent 5S technology.

As you can see, the Lean approach consists of stacked philosophies, principles and less specific methods or a wide variety of tools.

"If you learn only methods, you will be tied to your methods, but if you learn principles, you can devise your own methods." - Ralph Waldo Emerson 
Toyota's production system (TPS) is the source of LEAN principles and is now one of its fore-holdings. If, although primarily used in the production area (now a very multi-layered methodology, which has now become part of standardization, idea channeling, motivation, and atomization, together with a number of other commonly used methods, which, of course, can be used in other areas, such as the production of services. We must also bear in mind that Toyota itself designates humans as a fundamental value and the involvement of workers, by its interpretation we often see very big problems in practice and in our different corporate cultures.

Professor Blanchard (2010) [21] clearly highlights all this and not only the technological foundations (radically new perspectives) of the Lean system:

- All employees must be empowered to develop their company according to their ability and responsibility.

- Toyota's production system is based on a philosophy of continuous development and respect for people.

- Lean management is a waste eliminating strategy, not a cost-cutting strategy.

- Lean's practices must be closely linked to the process of the company's supply chain.

High-impact and all-in-one thinking on continuously implemented development Kaisen which is the built-in quality supplemented by the JIDOKA and JIT (just in time) principles, all of which aim to significantly reduce or eliminate losses, mainly through modifications that can increase lead times and the efficiency, flexibility and responsiveness of the system. [22] [23]

In their study, Pónusz and Sáska (2015) [24] examined how the creation of basic standards and the development of a well-transparent (visualized) working environment lead to the effective implementation of Lean philosophy. In the following illustration, Toyota's own concept was further developed in a house-like diagram, grouping Lean's philosophies, principles, methods and tools from strategy to operations, where it is very important that even "principles and philosophies" are grouped around methods and tools, the practical implementation, which ensures the desired greater efficiency. Based on the previous model of Liker (2008) [20].

The Toyota house symbol was first illustrated in the form of a house by Fujio Cho, a student of the famous engineer, Taiichhi Ohno. The purpose of the depiction was to show that, like the house, it is a structural system that needs strong foundations and supporting walls so that the goal, i.e. the roof, can be created. By analogy, a single weak link can weaken the entire system. Lean is a process management approach whose main goal is to create customer value and 
eliminate waste. "Lean provides the customer with fewer employees, fewer devices, less time, and less space, with fewer resources (more) value." [25]

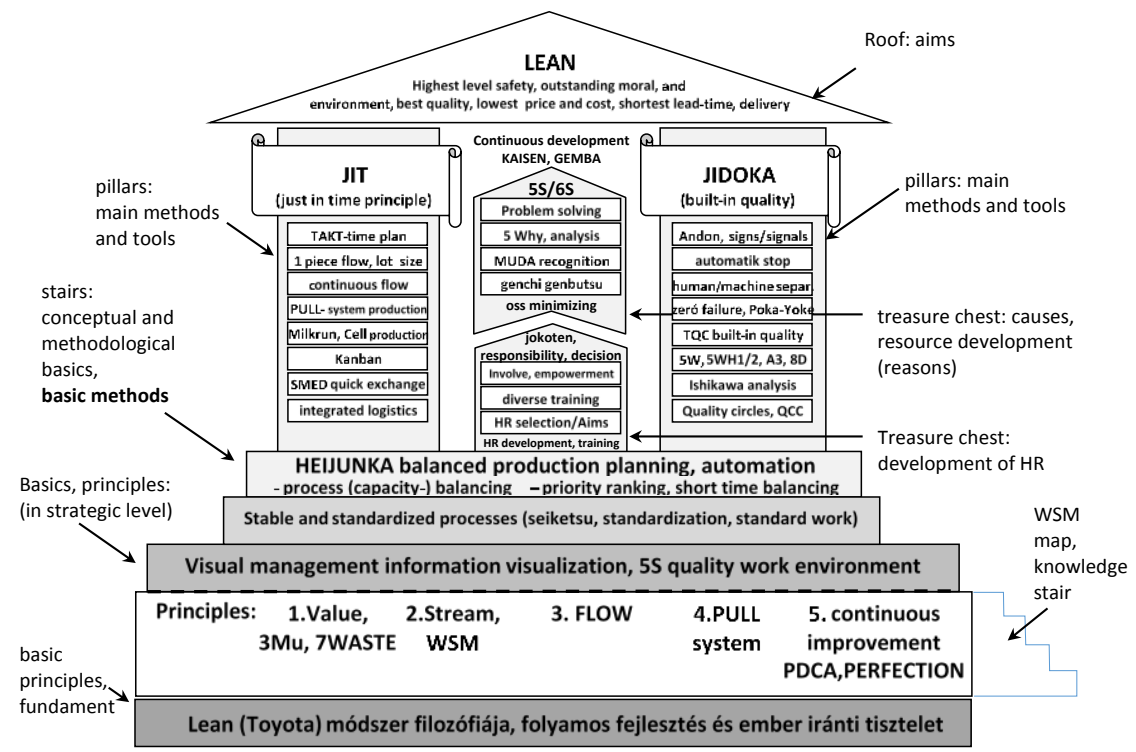

Figure 1

Lean tools and principles built on each other, as „Lean-house” concept (source: based on Liker (2008)

[20] but developed and reconstructed figure, and recommendation)

It is worth noting, that there may be many types of waste, since value-creating processes that do not fulfill some expectations, processes that do not add value, but are also necessary (MUDA I) and, processes to be minimized that do not add value but are necessary and the processes for eliminating losses that do not add value and are not necessary (MUDA II) In order to recognize all this, the necessary mentality and attitude are not easy to achieve, which have a re-effect on philosophical foundations. In some organizations, not only technology is evolving, but also the attitude, which makes it possible to recognize certain types of losses and accentuates at a particular point in development. Based on Taiichi Ohno and Womack (1996) [19], we can create the following categories according to our own interpretation, supplemented and significantly rephrased:

7 wastes of Lean - 7 main sources of loss (in extended generalized interpretation):

1) In relation to over-stocks (inventory): according to our interpretation, all inventory costs are originally losses, since they do not generate value while being in stock, but unreasonably more stocks than their smaller quantities are certainly a competitive disadvantage, i.e. a loss. Determining the extent and amount of it is very challenging which cannot be simplified into a mathematical problem (in fact, the challenge for the human intellect). 
2) Transportation loss: in the case of transport, it is not always the case that the buyer is willing to pay for it, thus significantly increasing the lead time of the value-creating processes and can also implement a number of unnecessary surpluses (e.g. extra road, extra time).

3) Defects and waste: i.e. all forms of defects are losses, but fewer people take into account their consequences, such as other production distractions, which are additional sources of loss, not to mention a disgruntled customer and a decrease in loyalty.

4) Waiting time: any time spent in a production system that does not generate value while resources are running out or, although not running out, capacity utilization does not reach a certain level and therefore production takes more time than necessary.

5) Over-processing: Any unnecessary activities or any work performed for which the customer no longer pays, but still necessary, e.g.: no matter how many times a product has to be checked, touched or repaired if the price is the same.

6) Motion: every wasteful movement any movement that someone has to make, but is not necessary, or in certain cases the whole movement may be completely unnecessary and it is only and exclusively subject of the procedure or arrangement.

7) Over-production (or over-ordering): any surplus to which there is no registered external or internal need, all that, what is not compatible with the pull principle.

In our investigation, our basic problem is the extent method of adjusting to demand levels. There are many approaches in the literature, from mathematical optimization to dynamic programming or simulation modelling. According to one possible concept, it is worth getting to know the distribution of needs as accurately as possible and we should try to adapt to them with the most accurate planning. The other possible concept is to increase the potential performance and flexibility of the service to a maximum and strive for an "immediate" response. The former is called MRP-based supply planning, while the latter is approached in JIT and LEAN systems. For the latter systems, the optimal solution is to keep inventory levels low and fast cycles, although it may be necessary to maintain and plan certain safety stock levels in both basic systems. In our case, we base our production on the concept that we try to adapt production as best we can to customer needs on a kind of synchronous production basis. The more we move towards flexible and synchronous production, the more problems arise in the nonequal utilization of capacities, which generates loss of efficiency or additional costs, or may result in periods when demand exceeds available capacities at any given moment, causing "lost" income (i.e. alternative costs). In the following illustration, we can see that in the case of large fluctuations, capacity scaling can be problematic for a number of reasons. 


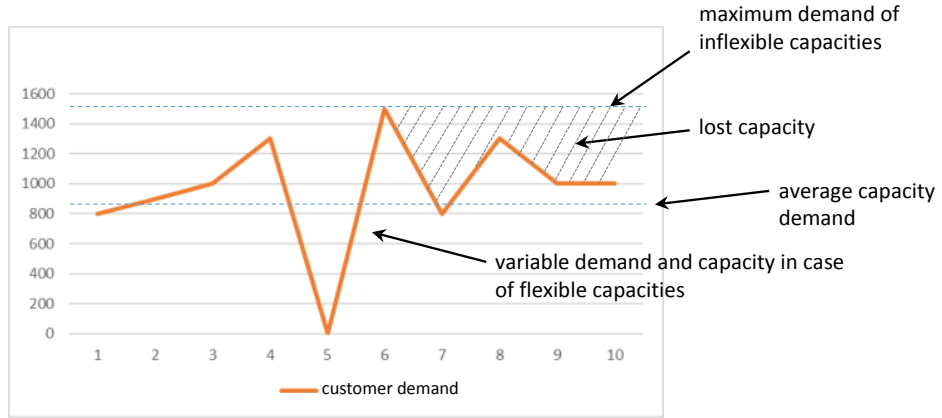

Figure 2

Volatility of demand (source: own editing from 2018 data of the examined company)

Some capacities cannot typically be changed flexibly (they should be scaled to maximum in a service strategy), while others may be more flexible and more free to follow changes in demand (typically with an extra premium cost, which is insured in relation to the constant level of capacity). Keeping inventory levels low and adapting production flexibly to customer needs does not always allow us to use capacity, which means additional costs for machinery and human resources, but if we keep capacities below the principled maximum, it is also possible that we will not be able to meet the demand peaks or even transfer them to a later date.

A smooth production schedule will make it possible to distribute needs more sensitively over time and thus make fuller use of capacities and reduce inventories further, at the cost of more transitions, more transition time and transition costs, provided that it can be reduced to a small level. Thinking in reverse, we can also plan the level of flexible capacities, which can be called a smoothed capacity. This way, you can manage both low inventory levels and fuller capacity utilization. After clarifying the forecasts and a more thorough assessment, it was established what distribution unmatched customer needs might appear in a possible next period. (These results are not referred to in this paper.)

If the production value chain is sufficiently complex, the completion cycles (beat, drum) of the bottleneck process will usually play the pace and "pulsation" of the entire system. In practice, we smooth out the needs for a period determined by forecasts and planned customer "takeaways" and provide this as a production plan, i.e. a requested capacity plan. Plans must be broken down to item number level. 


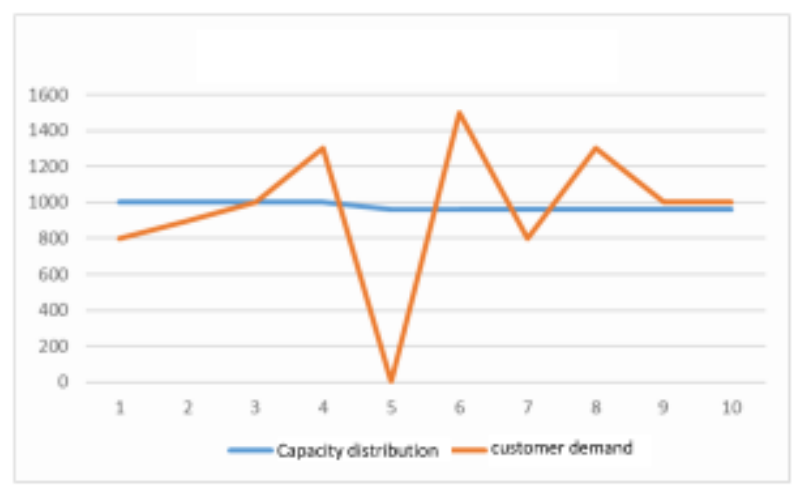

Figure 3

Smoothed capacity (source: own editing from 2018 data of the examined company)

The principle of consumption-based capacity control (i.e. consumption control) is broken down by item number like:

\section{1) Process flow (VSM)}

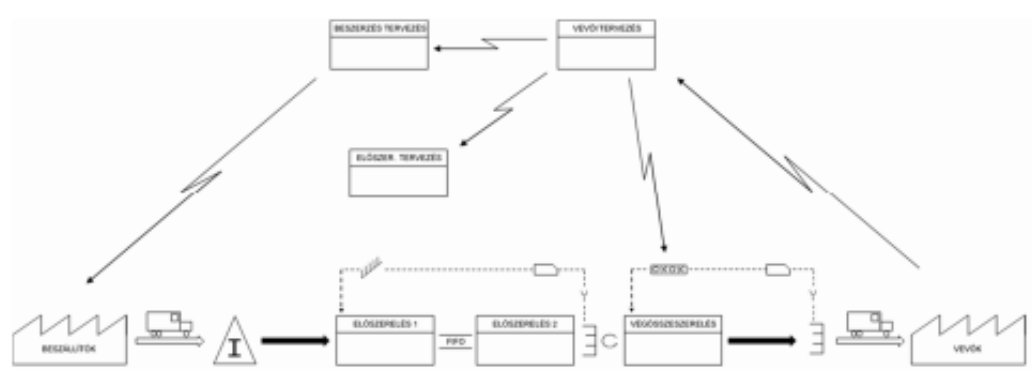

\section{Legend:}

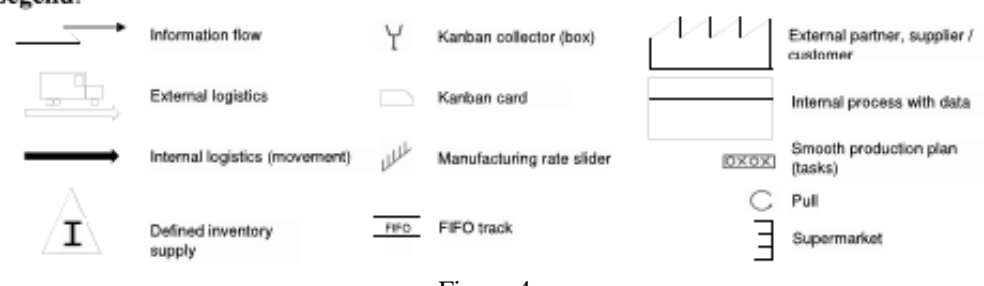

Figure 4

Smoothed capacity (source: own editing from 2018 data of the examined company)

\section{2) Interfaces:}

Production is separated from suppliers with "defined" stocks and from customers by Supermarket. The delivery cycles differ between our supplier and our customer. Two major areas are distinguished in internal processes (smaller processes within areas are less relevant and therefore not included): 
- Pre-assembly: pre-assembly1 and pre-assembly2 due to the complexity of the process, which essentially carry out the same process, but with different steps

- Final assembly

The following interfaces can be found in the production process:

- Raw material warehouse $\rightarrow$ Pre-assembly 1 and 2: the raw materials are seconded through an automatic system, according to your production plan according to your needs. The supply of materials is carried out by automated equipment on a specific cycle.

- Pre-assembly $1 \rightarrow$ Pre-assembly 2: the two pre-assembly lines are connected by a FIFO track (slider).

- $\quad$ Pre-assembly $2 \rightarrow$ Final assembly: supermarket kit is located between the two segments, this provides the possibility of separation. The existence of the Supermarket is also explained by the production of several different finished products from the pre-assembly item numbers and by the work of several different end-assembly lines from a pre-installed item number.

- Final assembly pushes the finished product to the finished product Supermarket.

3) Flow of information and materials

The flow of information can be divided into two parts:

- At specific intervals, system-wide data for calculations and planning within the design horizon.

- Information flow related to material flow and inventory levels (via Kanban circles).

System data shall be provided at fixed intervals, which may be weekly, bi-weekly, monthly, bimonthly, etc. The longer this design time horizon is, the more secure the customer forecasts, the more predictable the production system and the more predictable customer behavior.

In the value stream outlined above, the flow of information is:

- Customer planning receives orders from customers at item number level.

- Customer planning provides information about: orders.

1) In the direction of purchase $\rightarrow$ handling of raw material

2) Towards final assembly $\rightarrow$ production plan smoothed on the basis of capacity data and customer takeaways. 
3) In direction of pre-assembly planning $\rightarrow$ final assembly smooth production plan $+\mathrm{ABC}$ analysis pre-assembly broken down into item numbers.

- Pre-assembly planning:

- Pre-assembly capacity planning

- ABC analysis: separation and distribution of main running and exotic part-products on the basis of capacities.

- Kanban calculation and definition of supermarket stock levels (minimum maximum) for main running products, by part numbers.

Input information refers the value stream at several points and induces manufacturing activity. However, in addition to information from outside, there is also internal information, some of which are linked to physical material flow:

- The Kanban from supermarkets, until it is re-manufactured, is present as information in the system and flows backwards.

- At the stage of the process at which the product starts to be manufactured, Kanban information is stored on the products or their containers and the information and the product as a material go together through all processes all the way to the Supermarket until the customer or consumer "pulls" the product away from the Supermarket.

\subsection{Data and Information Needed for Operation and Analysis of Visualization}

One of the most important criteria to be able to operate consumption control is to be aware of the inventory and demand data that affects production in the short term, as well as sufficient information to make our decision more rational in some way. Experience has shown that the following 6 information are essential to create a real-time picture of operation:

1) Current stocks that are also available to the customer or consumer: item number and quantity, and location.

2) Not yet available to the customer, but stocks in progress, in production, and their degree of completeness. This is so-called: "pre-scheduled, moving stock."

3) Information on stocks already used by customers but not yet started in progress (e.g. re-rotated Kanbans awaiting production). If we are aware of the needs and capacities of our customers (and in an industrial environment, the least what we can do is to have a strong forecast of the expected needs, which is likely to be in sync with the stocks of the customers).

4) Pre-planned customer service or "takeaway". 
5) Planned downtimes in production (maintenance, breaks, etc.).

6) Current capacity utilization indicators.

Lean management has a set of tools designed to visualize deviations from standards, expected ranges, goals. A visual display is more expressive than any data or text. The portfolio of visual management is full of marking and signaling techniques that can be used. Such visualization systems include the Kanban, the production island Andon and standardized work, for example, as they make the thing, we need to pay attention to immediately visible and perceptible. These tools not only consciously cross lean systems, but they also provide information to those involved in the process and managers immediately when used, if they experience any differences.

Visuality is a basic concept (as shown in Figure 1) that allows the losses in processes to be visible and helps the decision-makers concerned determine the most appropriate form of intervention. It makes it easy for anyone to decide whether processes are going well or not, and then if not, what pre-drafted scheme is needed to intervene. An essential part of the day's work, it provides information about the current state of the production process (progress, delay, material shortage, machine failures, inventory status, etc.). It is also an effective tool for improving the production system by helping to identify problems and identify the location of problems. The first step in applying visual control is to create some sort of order that ensures transparency, so it is often created after 5S. An important criterion for Lean's production management tools is to comply with the principles of visual control, i.e. to provide easily understandable, clearly visible information on the state of production. [26]

The question arises as to what, where and how to display it in our case. Also, an additional question is who needs the impression, who will be the potential users?

All these issues are interconnected and functionally define each other. For example, you might want to display data at the point of production where things happen or where intervention is relevant. A common solution is to display at the very beginning or at the very end of the process if a process is short and well-bounded. If digital solutions are available, it is a good idea to display them digitally because they can appear at multiple points in production ("anywhere"). The question "how" means not only the digital term, but also the most expressive representation currently known, which has the greatest recognizable or expressive power for users. If this information is already collected in a bunch, it will be the colleagues working in the process and the direct managers responsible for the activity who need to know them, as well as those responsible for planning the activity, in close cooperation with the previous two. With all this in mind, there is only one question left: What should we display? 


\section{Results and Discussion}

From a view point of view, the data can be divided into two parts:

1) Real-time data: i.e. whenever I look at the board/monitor, I immediately have a picture of how the production is currently going. This is necessary to recognize whether everything is going well, or if there is any disruption that I need to respond to in a crisis. If the necessary data are all displayed at the same time and can be easily interpreted in their context, then it is possible to react quickly and make relevant decisions.

2) Historical data (statistics): all that has happened in the past, which can be natural or cumulative values. These impressions are important for improving the system and following the goals. We can use the statistics to make analyses and make estimates for the future.

With this theoretical approach in mind, I would like to outline the revised concept of the specialized consumption for implantation (pre-assembly) SMT control visualization of an automotive supplier company and to provide framework to the analytical procedures.

When designing a visual, the criterion is that the graphic/image/signal displayed is sufficiently expansive: it should be immediately able to provide a comprehensive knowledge about whether the current situation is appropriate or inappropriate. If you want a good visualization, you should also strive to make it easy to understand especially for users and even for those who do not have a deep knowledge of the process or production line (smart figure concept). For example, you can display charts instead of numbers, even if specific numbers remain "dataminable" (drillable). In the same way, we want to avoid anything that needs to be explained in text, because the text is subjective to the figure is clear. The time dimension of the representation is also important, in which the on-time (current) state becomes very important, especially when the management aspect comes to the fore. Also important are the colors, which are very expressive (red - not good, green - good, yellow - warning, etc.). Diagrams and symbols must wear their purpose, which may be indication, separation, coding, explanatory and interpretative meaning. It is a good idea to design different display levels and gradients, depending on the purpose and user of the report.

With all this in mind, the following visualization has been introduced. The firstround display is as follows:

1) On-time inventory tracking, according to data extracted from a database in every 30 minutes.

2) Follow supermarket entry and pick-up, broken down by day.

3) Follow supermarket levels, broken down to varying divisions, over the period of 30-minute data. 
Second-round display:

1) Display of current inventory level data

2) Supermarket entry and pick-up tracking, exact entry and take-away status.

3) Follow supermarket inventory according to the levels

4) Production plans and monitoring (historical data not described in this study)

\subsection{On-Time Inventory Tracking}

During Kanban circle calculation, for example, it is important to have a minimum and maximum level of inventory that activates specific reactions or escalations. For example, in the event of a decrease, the minimum inventory level triggers automated replenishment and escalation. In this case, the maximum level limits the total quantity of the item number that can be manufactured, and if there is no customer or user "pull" (order), a maximum of this amount of inventory can be created (upper buffer limit). These exact boundaries based on preliminary calculations provide the framework for displaying the current inventory level in each storage location. We want to mark the different levels and the current quantity in a distinct color, which has already been introduced in the production area under investigation. For the first-round display, it is sufficient to display only as a chart, while the second-round display must show the exact data: what is the minimum, what is the maximum, and what is the quantity of the current inventory level.

A) first round display

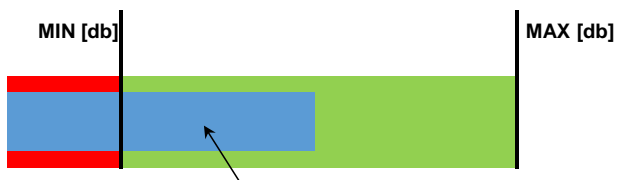

B) second round current inventory leve [psc] display

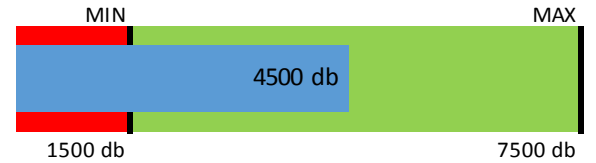

Figure 5

Inventory tracking visualization (source: own editing of the examined production area)

Data sources:

- The minimum and maximum levels are recalculated periodically from the data of the previous Kanban circle

- The current inventory level, can be retrieved from the always valid management information system used in the production area - samples 
should preferably be taken as quickly as possible, but at least more frequent than customer takeaways and/or synchronized with it in every 30 minutes.

Users:

- When assessing the current inventory level, the production planner

- When assessing the current inventory levels and starting a reaction/escalation, the direct management level, such as a shift manager.

\subsection{Supermarket Entry and Pick-Up Tracking}

In order to fit the shape of production and demand better, we need to look at the in and out flow of the Supermarket. We need to know what kind of load and picking have taken place during a specified period, which can be illustrated on the same scale and daily breakdown as a specially designed inflow and outflow chart. It is a good idea to show two or three weeks in the chart to create a bigger picture. In our experience, it is also very graphic if the figure shows the planned average pull.

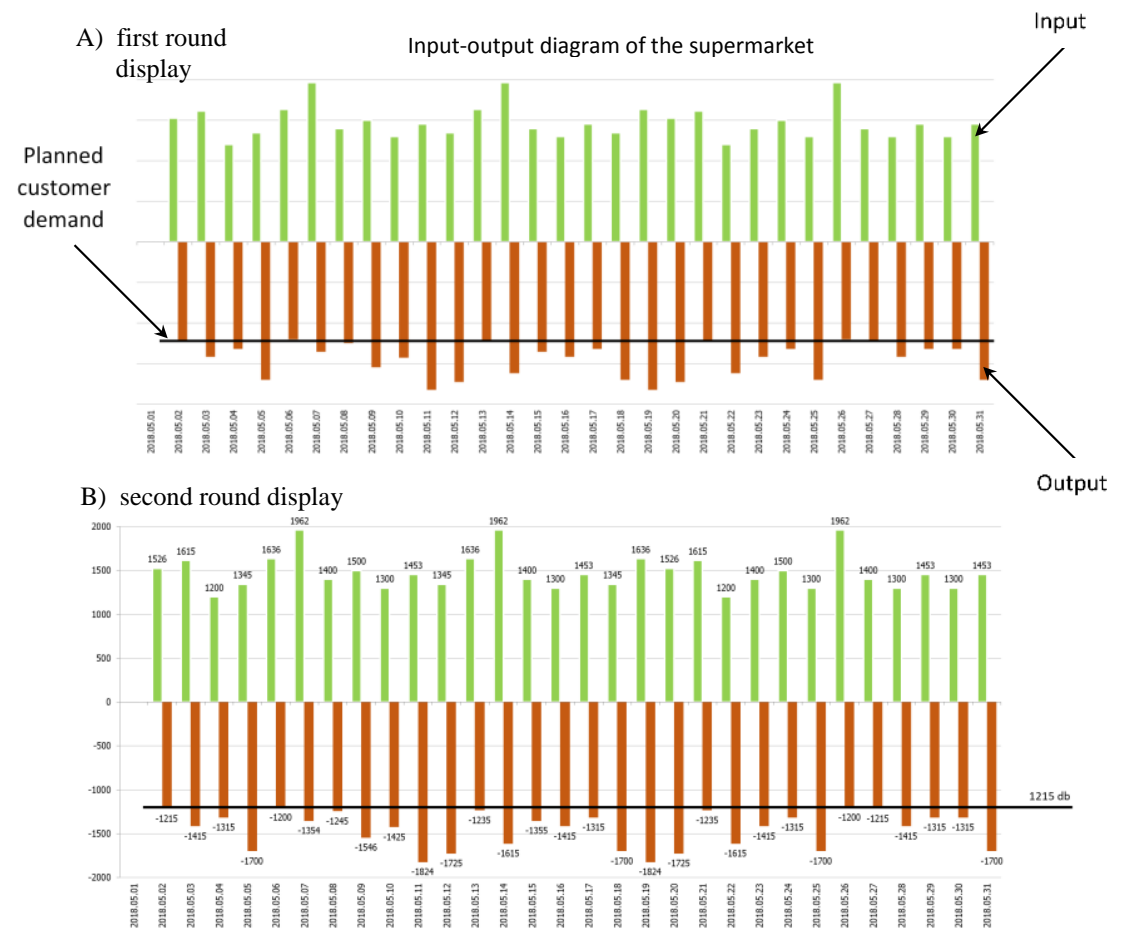

Figure 6

Supermarket loading and unloading visualization (source: own editing of the examined production area) 
For deeper analysis, you may need to display the data in more detail, even in intraday distribution. This is necessary where intra-day distribution is relevant.

Data sources:

- The planned customer (or consumer) takeaway can be derived from the smooth production plan of the final installation;

- The data displayed in daily (or intra-day) breakdowns can be extracted from the integrated management information (ERP, TPS, EIS, CAPP, ect.) system used in the production area.

Users:

- In the case of customer takeaway analysis, the production designer;

- If the minimum or maximum level is reached when the quantity and time of the customer's takeaway is reviewed and broken down the direct management level, such as the shift manager;

- Higher management level for customer takeaway, for analysis of the production volume and for system-level intervention.

After the visualization of the Supermarket loads and pic-ups, we consider the process-tape-like display to be a classic but very useful representation, illustrating the evolution within the desirable range in a clear form, as well as meeting our historical data needs about how the inventory has changed. For this visual, it is a good idea to use the same minimum and maximum levels that you use for the realtime inventory visual. For the sake of reality, it is advisable to tune the density of the data recording to the frequency of the takeaway, which in our case will be 30 minutes. In the final visualization, the process tape is displayed as a chart that is spread out so that the deviation can be better observed in one direction or another within the desired range.

A) first round display

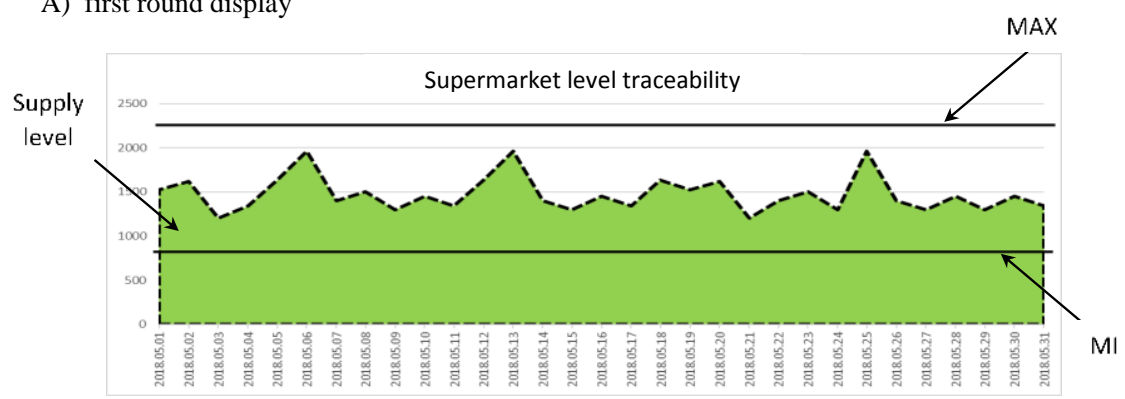

Figure 7

Supermarket level traceability visualization (source: own editing of the examined production area) 
For data sources, the real-time inventory level tracing data sources are the same. In the case of users, the production manager and management levels are relevant for us, and in the case of the latter for the assessment of systemic interventions.

\section{Conclusions and Suggestions}

During the work herein, we came to the following conclusions concerning the basics of a good and desirable, visualization:

- It is called a good system and a good visualization that ensures transparency, which is also the basis for additional key criteria, which have been formulated as a kind of directive.

- A good visualization must be such that, the decision-making person can see the differences immediately, be able to draw conclusions, depending on the aspect or perspective from which they are looking, i.e. who the person in charge is and what their task is.

- A good visualization must be different for different stakeholders, which can mean scalability (gradient) or different levels in practice, allowing different perspectives.

- A good visualization is the basis for quick and effective decisions, which should not be complicated or too complex, or probable and enabling multi-decision, it should always be clear.

- A good visualization must be able to test causal relations or, in the case of further questions, to acquire a further deeper level of knowledge (data mining, drill).

On this basis, we have managed to create a visual for the area in question that meets the examined theoretical background, the specifics of our organization and the criteria listed above and reviewed in the analysis. In our proposal, we stress, and in agreement with management, we represent that real-time (gauge type) visualization and backlog on the right scale should be prioritized in a visual that facilitates everyday activity and operation in order to facilitate operational decisions by displaying it in a sufficiently simple way (the simpler, the better).

In this work, we have described an entire development process, including some theoretical issues and their solutions. This application sample contributes to development of other companies with similar problems and could directly generate productivity improvement for many companies. These concepts can be used by companies of any size, including small and medium-sized enterprises. There is a wide range of manufacturing efficiency improvement methods available to the companies, such as Just in Time (JIT), or a range of lean manufacturing tools, but this method doesn't need notable investment or any reorganizing. The limitation of our methodology is a continuous and not so fluctuated supply, which is common in a LEAN environment, but perhaps, not so typical in other 
industries. We recommend this kind of visualization in all cases where the constant control and intervention is required.

The effective use of LEAN principles and applicability, incorporation or acceptance, within operations, is a major problem for many companies. This is why it is so important to conduct scientific research on the best practices. Therefore, we have developed a strict methodology, that consists of clearly defined steps, based on an analysis of Kanban needs. This solution identifies the key visualization factors for supply and provides the basis for a detailed examination of the related production efficiencies.

\section{References}

[1] C. Dawson and A. Henley, "Push versus pull entrepreneurship. An ambiguous distinction?" International Journal of Entrepreneurial Behavior \& Research, Vol. 18 No. 6, pp. 697-719, 2012, https://doi.org/10.1108/13552551211268139, downloaded: 23.09.2019

[2] U. Bititci, P. Cocca and A. Ates, "Impact of visual performance management systems on the performance management practices of organisations", International Journal of Production Research, Vol. 54, Issue 6, pp. 1571-1593, 2016, DOI: 10.1080/00207543.2015.1005770

[3] G. C. Parry and C. E. Turner, "Application of lean visual process management tools", Production Planning \& Control, Vol. 17, Issue 1, pp. 77-86, 2006, DOI: 10.1080/09537280500414991 (first published online: 21 Feb 2007)

[4] P. Burcher, "Closed- Loop MRP”, Operations Management, Vol. 10, and Strategic Management Journal, 22 January 2015A, https://doi.org/10.1002/9781118785317.weom100188

[5] P. Burcher, "Netting Process in MRP", Operations Management, Vol. 10, and Strategic Management Journal, 22 January 2015B, https://doi.org/10.1002/9781118785317.weom100188

[6] P. Burcher, "Safety Stocks in MRP", Operations Management, Vol. 10 and Strategic Management Journal, 22 January 2015C, https://doi.org/10.1002/9781118785317.weom100195

[7] A. Harrison and M. Lewis, "JIT and MRP/ERP", Operations Management, Vol. 10, 2015, https://doi.org/10.1002/9781118785317.weom100028

[8] Y. Eaidgah, A. A. Maki, K. Kurczewski, and A. Abdekhodaee, "Visual management, performance management and continuous improvement: A lean manufacturing approach", International Journal of Lean Six Sigma, Vol. 7, Issue 2, 2016, DOI: 10.1108/IJLSS-09-2014-0028 (first published: 6 June 2016)

[9] E. Y. Gorodov, and V. V. Gubarev, "Analytical Review of Data Visualization Methods in Application to Big Data", Journal of Electrical 
and Computer Engineering, Vol. 2013, Article ID 969458, p. 7, 2013, https://doi.org/10.1155/2013/969458

[10] N. Bilalis, G. Scroubelos, A. Antoniadis, D. Emiris, and D. Koulouriotis, "Visual factory: basic principles and the 'zoning' approach", International Journal of Production Research, Vol. 40, No. 15, pp. 3575-3588, 2002 (first published online: $14 \quad$ Nov 2010) https://doi.org/10.1080/00207540210140031

[11] C. Herron and P. M Braiden, "A methodology for developing sustainable quantifiable productivity improvement in manufacturing companies", International Journal of Production Economics, Vol. 104, No. 1, pp. 143153, 2006, https://doi.org/10.1016/j.ijpe.2005.10.004

[12] Bhasin, S., "Lean and performance measurement", Journal of Manufacturing Technology Management, Vol. 19, No. 5, pp. 670-684, 2008, https://doi.org/10.1108/17410380810877311

[13] A. Tezel, L. Koskela and P. Tzortzopoulos, "Visual management in production management: a literature synthesis", Journal of Manufacturing Technology Management, Vol. 27, No. 6, pp. 766-799, 2016, https://doi.org/10.1108/JMTM-08-2015-0071

[14] S. Liff and P. A. Posey,"Seeing is Believing: How the New Art of Visual Management Can Boost Performance Throughout Your Organization", Publisher: AMACOM, New York, NY. 2004 (first published on amazon: February 27, 2007) ISBN-13 : 978-0814400357, DOI: 10.5860/choice.424137

[15] T. Joosten, I. Bongers and R. Janssen, "Application of lean thinking to health care: issues and observations", International Journal for Quality in Health Care, Vol. 21, No. 5, pp. 341-347, 2009

[16] Z. Radnor, "Transferring lean into government", Journal of Manufacturing Technology and Management, Vol. 21, No. 3, pp. 411-428, 2010

[17] M. O. Ahmad, J. Markkula and M. Oivo, "Kanban in software development: a systematic literature review", $39^{\text {th }}$ IEEE Conference on Software Engineering and Advanced Applications (SEAA), pp. 9-16, 2013

[18] K. J. Caterall, "A Lean view on an Eastern Cape Logistics Service Provider" Publisher: Nelson Mandela Metropolitan University - Faculty of Business and Economic Sciences, https://vital.seals.ac.za/vital/access/manager/PdfViewer/vital: 8713/SOURCEPDF?viewPdfInternal=1, p. 129, 2008

[19] J. P. Womack and D. T. Jones, "Lean Thinking Banish Waste and Create Wealth in Your Corporation" Publisher: Simon \& Shuster, New York, p. 400, 1996, ISBN: 9781439135952 
[20] J. K. Liker, ”A Toyota-módszer: 14 vállalatirányítási alapelv, (The Toyota Way - 14 management principles)," (in Hungarian edition by T. Z. Polyánszky) Publisher: HVG, Budapest 2008, ISBN 978-963-9686-43-4

[21] D. Blanchard, "Supply Chain Management - Best practices", Publisher: Hoboken, New Jersey, John Wiley \& Sons, Inc. p. 215, 2010 (Second edition)

[22] B. Gyenge, H. Szilágyi and T. Kozma, "Lean menedzsment alkalmazása szolgáltatóvállalat esetében, (Lean management in case of logistic service provider company)," Vezetéstudomány (Budapest Management Review), No. 4, p. 46, Budapest, 2015, http://gazdalkodastudomany.unicorvinus.hu/index.php?id $=59089$

[23] T. Kozma and M. Pónusz, "Ellátásilánc-menedzsment elmélete és gyakorlata - alapok, (Supply Chain Management principles and practice)," Publisher: Károly Róbert Kutató - Oktató Közhasznú Nonprofit Kft., Gödöllö, 2016

[24] M. Pónusz and Zs. Sáska, "Lean menedzsment eszközök gyakorlati alkalmazása Folyamatmenedzsment kihívásai, (Practical application of Lean management tools Challenges of process management)," in Döntési pontok, kapcsolatok és együttmüködési stratégiák a gyakorlatban (Decision points, relationships and collaboration strategies in practice). Publisher: Szolnoki Főiskola (Szolnok College later: Naeumann János University), Szolnok 2015, ISBN 978-615-5570-02-5, http://fulltext.szie.hu/jadox/portal/ displayImage.psml?docID $=15876 \&$ secID $=17291$

[25] K. Demeter, "Termelés, szolgáltatás, logisztika. Az értékteremtés folyamatai, (Production, service, logistics. Value creation processes,)" Published: Wolters Kluwer Kiadó, Budapest, p. 159, 2014

[26] J. Kosztolányi and G. Schwahofer, "Lean szótár, (Lean dictionary)" Publisher: Kaizen PRO Kft. Budapest, 2012 